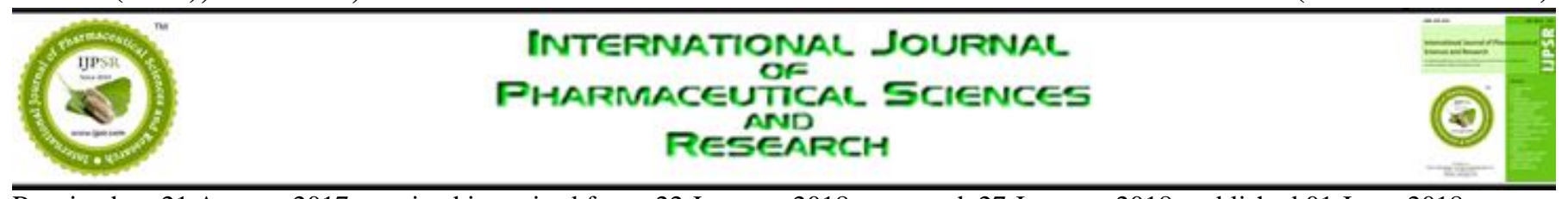

Received on 21 August, 2017; received in revised form, 22 January, 2018; accepted, 27 January, 2018 ; published 01 June, 2018

\title{
COMPARATIVE STUDY OF ROPIVACAINE WITH CLONIDINE AND ROPIVACAINE ALONE IN SUPRACLAVICULAR BRACHIAL PLEXUS BLOCK
}

\author{
Devang Priyadarshi *, Deepa Gondalia and Vandana Parmar \\ Pandit Deendayal Upadhyay Medical College, Rajkot - 360001, Gujarat, India.
}

Keywords:

Ropivacaine $(0.5 \%)$,

Adjuvant, Clonidine, Supraclavicular brachial plexus block

Correspondence to Author:

Dr. Devang Priyadarshi

B- 301, Silver Park Apartment, Opposite Shardamandir School, Ambawadi, Ahmedabad - 380006, Gujarat, India.

E-mail : devang4764@gmail.com
ABSTRACT: Background: Brachial plexus block provides minimal systemic impairment and excellent localized postoperative analgesia for upper extremity surgery. LA's such as lignocaine, bupivacaine and ropivacaine are widely used along with adjuvant to improve the quality, onset and duration of block and to decrease postoperative analgesic requirement and systemic side effects. Adjuvant like $\alpha-2$ agonist (Clonidine), opioids etc. are been added to LA's. Clonidine is an imidazoline derivative with $\alpha-2$ adrenergic agonistic activity. There has been seen a potentially clear synergism between clonidine and ropivacaine in various regional block anaesthesia. Material and Methods: In this randomized doubled blind controlled study, a total of 60 ASA grade I or II patients were taken and randomly allocated into 2 groups comprising 30 patients in each group. Group $\mathrm{R}$ includes patients which were given $30 \mathrm{ml}$ of $0.5 \%$ ropivacaine + $2 \mathrm{ml}$ normal saline and in Group RC $30 \mathrm{ml}$ of $0.5 \%$ ropivacaine with $2 \mu \mathrm{g} / \mathrm{kg}$ clonidine in $2 \mathrm{ml} \mathrm{NS}$. Sensory function was tested using pinprick and motor with concomitant inability to move the wrist and hand and the first analgesic request was noted. Statistical Analysis: Results were expressed as mean and standard deviation. $\mathrm{P}$ value of $<0.05$ was considered statistically significant. Results: Duration of sensory, motor blockage and analgesia lasted longer in Group RC than Group R. There was no statistically significant in hemodynamic parameters, side effects and complication. Conclusion: Clonidine produces faster onset and longer duration of sensory, motor blockage, analgesia without any significant side effect and complication when used as an adjuvant to ropivacaine for supraclavicular brachial plexus block.
INTRODUCTION: The supraclavicular brachial plexus block provides anaesthesia of entire upper extremity in most consistent manner. Brachial plexus blockade for upper limb surgeries is advantageous as the effect of drug is limited to the part of the body to be operated upon.

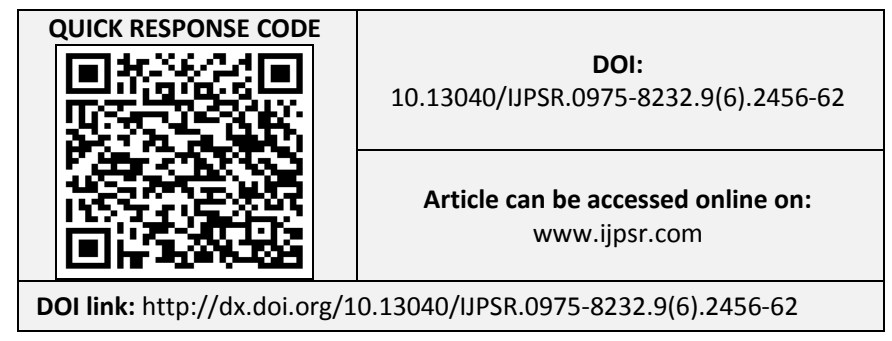

A commonly used drug for this technique is bupivacaine $0.5 \%$ which is a well established long acting local anaesthetic, which like all amide anaesthetics has been associated with cardiotoxicity when used in high concentration or when accidentally administered intravascularly.

As with other fields, regional anaesthesia too, has undergone major developments, both in techniques and drug availability. Ropivacaine was thus developed after it was noted that bupivacaine was associated with significant number of cardiac arrests. Ropivacaine is a new long acting local anaesthetic drug belonging to the amino amide 
group. Ropivacaine and bupivacine belong to pipecoloxylidides group of local anaesthetics. It is a pure S(-) enantiomer, unlike Bupivacaine, which is a racemate, developed for the purpose of reducing potential toxicity and improving relative sensory and motor block profiles ${ }^{1}$.

Addition of adjuvant drugs to the local anaesthetic might improve quality, onset and duration of block and decrease postoperative analgesic requirement and systemic side effects ${ }^{2}$. Opioids, clonidine, ketamine and prostigmine have been added to local anaesthetics and injected extradurally, intrathecally or in nerve plexuses for a more intense and prolonged analgesia $3,4,5,6,7,8$. Opioids are commonly added to local anaesthetic solutions to increase intensity and duration of anaesthesia by acting on opioid receptors present on the nerve terminals ${ }^{9,10}$. However, fentanyl has some side effects as vomiting and respiratory depression ${ }^{7}$. Clonidine is a selective Alpha-2 adrenergic agonist with some Alpha-1 agonist property. In clinical studies, the addition of clonidine to local anesthetic solution improved peripheral nerve blocks by reducing the onset time improving the efficacy of the block during surgery and extending postoperative analgesia.

Clonidine enhances or amplifies the sodium channel blockade action of local anesthetics by opening up the potassium channels resulting in membrane hyperpolarization, a state in which cell is unresponsive to excitatory input ${ }^{11,12,13}$.

Thus clondine has been used as an adjuvant to local anesthetics to prolong the duration of effect of local anaesthetic drugs.

We decided to evaluate efficacy of ropivacaine $0.5 \%$ alone in brachial plexus block in upper limb surgeries and its clinical comparison with ropivacaine $0.5 \%$ with clonidine $2 \mu \mathrm{g} / \mathrm{kg}$ via supraclavicular approach.

Aims and Objectives of Study: To determine onset and duration time for sensory block, motor block, analgesia and study effects of drugs on vital parameters (pulse rate, blood pressure, respiratory rate and spo2), side effects and complication.

MATERIAL AND METHODOLOGY: The study of clinical comparison of $0.5 \%$ Ropivacaine and Clonidine with $0.5 \%$ Ropivacaine alone in supraclavicular brachial plexus block for upper limb surgical procedures was carried out in P.D.U. Medical College and Hospital, Rajkot during the year December 2014 to June 2016 after approval of Institutional Ethics Committee, P.D.U. Medical College and Hospital, Rajkot.

We recruited 60 patients of adult age group (18 - 60 years) of ASA grade of I or II admitted for any kind of elective surgeries on upper limb for our randomized prospective double blind controlled trial. Patients with history or evidence of skin infection, injury at supraclavicular site, drug allergy, sepsis, pregnancy, upper limb neurological deficit, bleeding disorders or patient on anticoagulant therapy, other than ASA grade I or II and neuromuscular disease were not included in this study.

Randomization was done with the use of sealed envelope which contain computer generated random numbers. Odd numbers indicate Group $\mathrm{R}$ and even numbers indicate Group RC. (Computer generated random number table is attached here with). Double blinding was done for the conducted study. Person who is giving block and person observing the effect of the block were different and were blinded to the drug given to the patients.

All the patients underwent pre-anaesthetic check up before surgery and all the routine and specific investigations were noted. The patients were kept electively nil per oral for 10 hours before surgery and prior to operation patients were explained about the procedure and a written informed consent taken. Intravenous line secured in all the patients. Standard monitors like ECG, NIBP, and pulseoximeter were applied and patient's baseline parameters like pulse, blood pressure, respiratory rate, $\mathrm{SpO} 2$ were recorded. Patients were premedicated with:

Inj. Glycopyrrolate $(0.2 \mathrm{mg})$ i.v.

Inj. Ondansetron (4 mg) i.v.

Inj. Ranitidine (50 mg) i.v.

Technique: For performing brachial plexus blockade through supraclavicular approach we used classical technique. After proper patient positioning with the patient supine, the head turned to opposite side, and the shoulder depressed, under strict 
aseptic and antiseptic precautions midclavicular point, external jugular vein and subclavian artery pulsation were identified. About $1 \mathrm{~cm}$ above the midclavicular point just lateral to subclavian artery pulsation, a 23 gauge 1.5 inch needle was introduced and directed caudal, downward and medially toward the first rib until paraesthesia was noted along radial and lunar distribution or motor response was elicited. Here anaesthetic solution is injected beneath the deep fascia before every incremental dose negative aspiration for blood was performed to avoid any intravascular placement. $32 \mathrm{ml}$ of respective drug will be injected depending on whether patient is allotted to either group $\mathrm{R}$ and RC.

Group R: Inj. Ropivacaine (0.5\%) - 30ml + Inj. Normal Saline 2ml

Group RC: Inj. Ropivacaine (0.5\%) - 30ml + Inj. Clonidine $2 \mu \mathrm{g} / \mathrm{kg}$ in $2 \mathrm{ml}$ Normal Saline.

Pulse rate, blood pressure, oxygen saturation and respiratory rate were recorded before and after the procedure, and there after every $5 \mathrm{~min}$ after the administration of block till an hour irrespective of duration of surgery. Simultaneously patient was assessed for any complications like nausea, vomiting, chest pain, coughing, convulsion, hypotension, bradycardia and respiratory depression.

Sensory and motor function was evaluated before the block and every 2 min for initial 30 min after the block, and then every 30 minute till patient regains normal sensations after the block.

Sensory block and analgesia were assessed by pinprick, C4 to T2 dermatome and graded according to

0 - Normal response to pin prick

1 - Dull response to pin prick (onset)

2 - No response to pin prick (peak)

Onset time for analgesia was defined as the time taken from the end of the injection to the first dull response to pinprick in the distribution of any of the three sensory nerves in the hand.

Onset time for sensory blockade was defined as the time taken from the end of the injection and the complete development of anaesthesia (no sensation reported to pinprick) in all three sensory nerves in the hand.

Onset of motor block was assessed by asking the patient to do abduction of arm and flexion of forearm.

Motor block was assessed by modified Lovett's grade as

\section{Grade 6: Normal}

Grade 5: Slightly reduced muscular force

Grade 4: Pronounced reduction

Grade 3: Slightly impaired mobility

Grade 2: Pronounced mobility impairment

Grade 1: Almost complete paralysis

Grade 0: Complete paralysis

Onset time for motor blockade was defined as the time from the end of the injection to time when patient was unable to abduct arm at shoulder.

Total duration of motor blockade was defined as time interval between onset of motor block and complete recovery of motor power.

Total duration of sensory blockade was defined as time interval between onset of sensory block and complete recovery of sensation.

Total duration of analgesia was defined as time interval between onset of analgesia and requirement of first rescue analgesic.

When patient feel pain, rescue analgesia was administered in the form of Inj. Diclofenac sodium $1.5 \mathrm{mg} / \mathrm{kg}$ intravenously. Evaluation was stopped and time for need of first analgesia was noted.

Both groups were compared for onset and total duration of analgesia, sensory and motor blockade. All the data were filled up in proforma.

Statistical Analysis: All the data were recorded in Microsoft Excel 2007. Mean as well as Standard Deviation (SD) were calculated. Statistical difference between two groups was determined using "unpaired student t- test". The results were considered significant if $\mathrm{P}$-value is $<0.05$ and considered as highly significant if $\mathrm{P}$-value is < 0.001 . 
RESULT: Our study includes 60 patients of adult age group (18 - 60 years) of ASA grade of I or II. 60 patients were divided into 2 groups, having 30 patients each group.

We observed that Mean time of onset of analgesia in Group R was $14.8 \pm 0.80 \mathrm{~min}$ and in Group RC was $10.4 \pm 1.37 \mathrm{~min}$, which was comparable and statistically highly significant. ( $p$ value $<0.001$ ). In our study the mean duration of analgesia in Group $\mathrm{R}$ was $453.66 \pm 8.80 \mathrm{~min}$ and in Group RC was 583 $\pm 17.25 \mathrm{~min}$ which was statistically highly significant (p value < 0.001) Fig. 1.

In our study mean time of onset of sensory block in Group $\mathrm{R}$ was $14.8 \pm 0.80 \mathrm{~min}$ and in Group RC was $10.4 \pm 1.37$ min which was statistically highly significant. ( $p$ value $<0.001$ ) and mean time of duration of sensory block in Group R was $392.16 \pm$

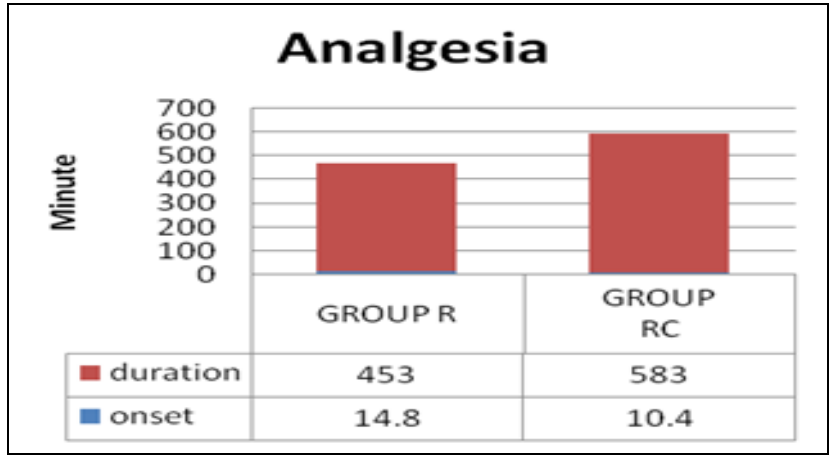

FIG. 1: ONSET AND DURATION OF ANALGESIA

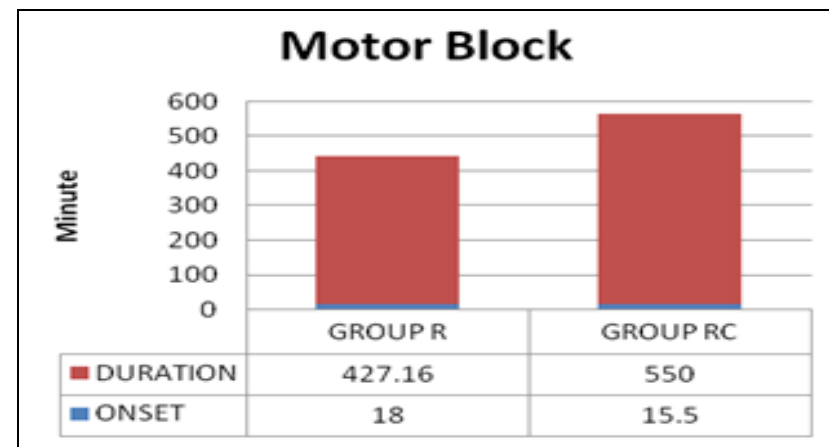

FIG. 3: ONSET AND DURATION OF MOTOR BLOCK

DISCUSSION: For brachial plexus block a drug that has a fast onset, long duration and minimal toxicity profile could be an advantage. Bupivacaine is a well established long acting local anaesthetic, which like all amide anaesthetics has been associated with cardiotoxicity when used in high concentration or when accidentally administered intravascularly. Subsequently it was found that propyl derivatives of pipecoloxylidides were less toxic than butyl derivatives.
$7.84 \mathrm{~min}$ and in Group RC was $480.5 \pm 17.03 \mathrm{~min}$ which was statistically highly significant ( $\mathrm{p}$ value < 0.001) Fig. 2.

In our study the mean time of onset motor blockade in Group $\mathrm{R}$ was $18 \pm 1.08 \mathrm{~min}$ and in Group RC was $15.5 \pm 1.79$ min which was statistically highly significant. ( $\mathrm{p}$ value $<0.001$ ) and mean time of duration of motor blockade in Group $\mathrm{R}$ was 427.16 $\pm 8.06 \mathrm{~min}$ and in Group RC was $550 \pm 16.24 \mathrm{~min}$ which was statistically highly significant ( $\mathrm{p}$ value < 0.001) Fig. 3.

In our study, blood pressure Fig. 4, pulse rate, respiratory rate and oxygen saturation remained stable throughout the procedure as they did not differ significantly during the study period and no statistically significant difference was observed in both groups ( $\mathrm{p}$ value $>0.05$ ).

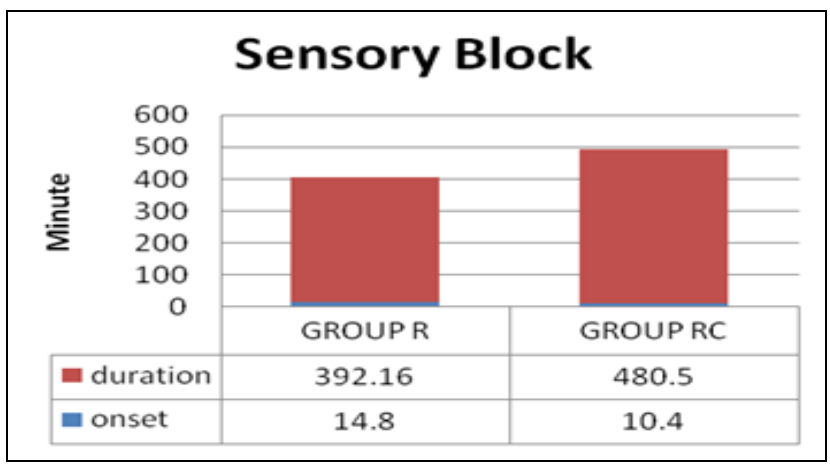

FIG. 2: ONSET AND DURATION OF SENSORY BLOCK

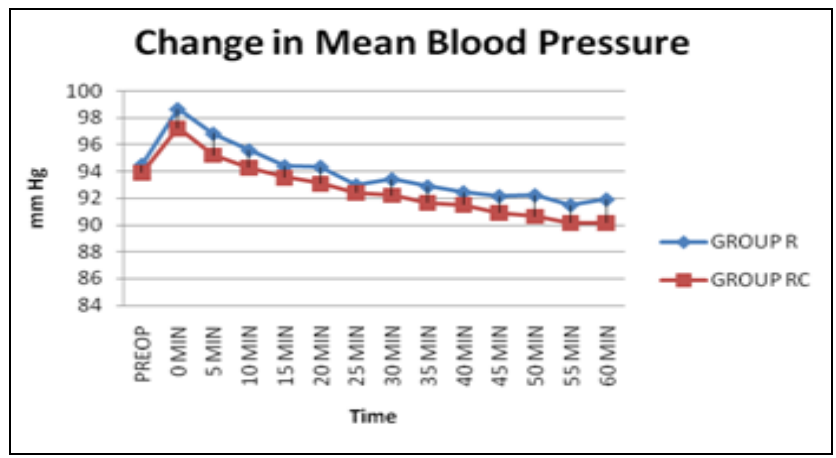

FIG. 4: CHANGE IN MEAN BLOOD PRESSURE

As with other fields, regional anaesthesia too, has undergone major developments, both in techniques and drug availability. One of the first local anaesthetic agents that emerged as a possible replacement for bupivacaine was Ropivacaine. On reviewing the literature, present study was undertaken to compare effect of Ropivacine with clonidine and Ropivacaine alone in brachial plexus block via supraclavicular approach for upper limb surgical procedures. 
The dose of ropivacaine varies with the anaesthetic procedure, the area to be anaesthetized, the vascularity of tissues, degree of muscle relaxation required, duration of anaesthesia desired and physical condition of patient. Ropivacaine was used in doses of $75-300 \mathrm{mg}$ in brachial plexus block in various studies. In general, the maximum dose is $3 \mathrm{mg} / \mathrm{kg}$ for ropivacaine. In our study we used $30 \mathrm{ml}$ ropivacaine $0.5 \%$ and $2 \mu \mathrm{g} / \mathrm{kg}$ body weight clonidine for brachial plexus block.

Rohan B, Singh PY et al., ${ }^{14}$ (2014) on addition of clonidine or lignocaine to ropivacaine for supraclavicular brachial plexus block in which Patients in all three group received $20 \mathrm{ml}$ of $0.75 \%$ ropivacaine. In addition to that, patients in clonidine group received $1 \mathrm{ml}$ of clonidine (150 $\mu \mathrm{g}$ ) plus $9 \mathrm{ml}$ of saline, patient in lignocaine group received $10 \mathrm{ml}$ of $2 \%$ lignocaine with Adrenaline (1:2000000) and patients in the control group received $10 \mathrm{ml}$ of saline. They found that earlier onset of Analgesia, onset of sensory and motor block in clonidine group compared to analgesia using Ropivacaine alone. This was similar to our study.

Shobhana Gupta, Hina Niraj Gadani et al., ${ }^{15}$ (2015) who studied A comparison between ropivacaine $30 \mathrm{ml}(0.75 \%)$ and ropivacaine $30 \mathrm{ml}$ $(0.75 \%)$ with clonidine $150 \mu \mathrm{g}$ as an adjuvant in brachial plexus block through supraclavicular approach. They found that mean onset of analgesia was faster in ropivacaine with clonidine group which was $4.36 \pm 0.81 \mathrm{~min}$ than in Ropivacine alone group which was $4.84 \pm 0.65 \mathrm{~min}$. This was similar to our study. Khageswar Raut, Basant Kumar Pradhan et al., ${ }^{16}$ (2015) who studied The Effects of two Different Doses of Clonidine as Adjuvant to Ropivacaine in Supraclavicular Brachial Plexus Block. They found that mean onset of analgesia was faster in group A receiveing clonidine $2 \mu \mathrm{g} / \mathrm{kg}$ which was $10.42 \pm 505 \mathrm{~min}$ than group $\mathrm{B}$ receiving clonidine $1 \mu \mathrm{g} / \mathrm{kg}$ which was $15.83 \pm 6.51$. This was similar to our study.

Chatrath V, Sharan R et al., ${ }^{17}$ (2015) on Comparative evaluation of $0.75 \%$ ropivacaine with clonidine and $0.5 \%$ bupivacaine with clonidine in infraclavicular brachial plexus block. Infraclavicular block was performed with $30 \mathrm{ml}$ of $0.75 \%$ ropivacaine plus $150 \mu \mathrm{g}$ clonidine in Group
$\mathrm{R}$ and $30 \mathrm{ml}$ of bupivacaine plus $150 \mu \mathrm{g}$ clonidine in Group B. They found that onset time of Analgesia in Group $\mathrm{R}$ was $5.80 \pm 5.12 \mathrm{~min}$ compare to Group B which was $4.87 \pm 1.46 \mathrm{~min}$. This was also similar to our study.

Birbal Baj, Vandana Tyagi et al., ${ }^{18}$ (2013) on a comparative study of effects of clonidine added to ropivacaine versus plain ropivacaine during supra clavicular brachial plexus block in which total of 60 ASA Grade I to IV patient were taken and randomly allocated into 2 groups comprising 30 patients in each. Group I (control group) included patients which were given $30 \mathrm{ml}$ of $0.75 \%$ ropivacaine (225 $\mathrm{mg}$ ) and Group II (study group) included patients which were given $30 \mathrm{ml}$ of $0.75 \%$ ropivacaine $(225 \mathrm{mg})$ with $0.4 \mathrm{ml}(60 \mu \mathrm{g})$ clonidine. They found that mean duration of Analgesia in Group II was $576.96 \pm 81.45 \mathrm{~min}$ which was prolonged than Group I which was $442.14 \pm 86.47 \mathrm{~min}$, mean duration of sensory block in Group II was $551.07 \pm 84.09 \mathrm{~min}$ compared to group I which was $422.50 \pm 87.75 \mathrm{~min}$ and mean duration of Motor block in Group II was $533.75 \pm 84.36$ min compared to group I which was $403.39 \pm 87.91 \mathrm{~min}$. This was similar to our study.

Asad Mohammad, Sangeeta Goel et al., ${ }^{19}$ (2016) on Clonidine as an Adjuvant to Ropivacaine in Supraclavicular Brachial Plexus Block in which 60 adult ASA grade I and II patients scheduled for upper limb surgeries were randomized to receive either $30 \mathrm{ml}$ of $0.5 \%$ Ropivacaine $+0.6 \mathrm{ml}$ saline (Group R) or $30 \mathrm{ml} 0.5 \%$ Ropivacaine and $0.6 \mathrm{ml}$ $(100 \mu \mathrm{g})$ of Clonidine (Group RC) in supraclavicular block. They found that mean duration of analgesia in group RC was $912 \pm 75.8$ min which was prolonged than in group $\mathrm{R}$ which was $793 \pm$ 75.4 min, mean duration of Sensory block in group $\mathrm{RC}$ was $885 \pm 57.8$ min compared to group $\mathrm{R}$ which was $676 \pm 48.46 \mathrm{~min}$ and mean duration of Motor block in group RC was $770 \pm 38.9 \mathrm{~min}$ compared to group $\mathrm{R}$ which was $470 \pm 38.9 \mathrm{~min}$. This was similar to our study.

Chinar Patel, Hetal Parikh et al., ${ }^{20}$ (2014) on clonidine as adjuvant to $0.75 \%$ ropivacaine in supraclavicular brachial plexus block for post operative analgesia in which Group I patients received $40 \mathrm{ml}$ of $0.75 \%$ Ropivacaine $+1 \mathrm{ml}$ of normal saline and Group II- patients received the 
same block with $40 \mathrm{ml}$ of $0.75 \%$ Ropivacaine +2 $\mu \mathrm{g} / \mathrm{kg}$ clonidine. They found that mean duration of Analgesia in Group II was $809 \pm 101.6$ min and in Group I was $563 \pm 78.05$ min which was similar to our study. Usha Bafna, Naresh Yadav et al., ${ }^{21}$ (2015) on Comparison of $0.5 \%$ ropivacaine alone and in combination with clonidine in supraclavicular brachial plexus block. Patients in Group $1(\mathrm{n}=40)$ received $28 \mathrm{ml}$ of $0.5 \%$ ropivacaine and in Group $2(\mathrm{n}=40)$ received $28 \mathrm{ml}$ of $0.5 \%$ ropivacaine with clonidine $(2 \mu \mathrm{g} / \mathrm{kg}$ bodyweight). They found that mean duration of Analgesia in Group 2 was $1016.9 \pm 170.1 \mathrm{~min}$ which prolonged than Group 1 which was $488 \pm 65.04$. This was similar to our study.

Dr. Sidharth Sraban Routray, Dr. Debdas Biswal et al., ${ }^{22}$ (2013) on the effects of Clonidine on Ropivacaine in Supraclavicular Brachial Plexus Block. They found that mean duration of Analgesia in Group A having $150 \mu \mathrm{g}$ Clonidine was $586 \pm$ 56.8 min which was prolonged than Group B (without clonidine) $465.8 \pm 62.5 \mathrm{~min}$, mean onset time of Sensory block in group A was $10.44 \pm 5.7$ min and in group B was $15.85 \pm 6.55$ min, mean duration of Sensory block in group A was $484.15 \pm$ $63.4 \mathrm{~min}$ and in group B was $390.85 \pm 72.65 \mathrm{~min}$, mean onset time of Motor block in group A was $14.35 \pm 7.8 \mathrm{~min}$ and in group B was $18.55 \pm 7.64$ min and mean duration of Motor block in group A was $550 \pm 60.3 \mathrm{~min}$ and in group $\mathrm{B}$. This was similar to our study.

Kalyani Nilesh Patil, Noopur Dasmit Singh et al., 23 (2015) on Clonidine as an adjuvant to ropivacaine - induced supraclavicular brachial plexus block for upper limb surgeries in which A total of 60 adult patients were randomly recruited to two groups of 30 each: Group I: $30 \mathrm{ml} 0.75 \%$ ropivacaine $+1 \mathrm{ml}$ normal saline. Group II: $30 \mathrm{ml}$ $0.75 \%$ ropivacaine $+1 \mu \mathrm{g} / \mathrm{kg}$ clonidine diluted to $1 \mathrm{ml}$ with normal saline. They found that mean duration of Analgesia in group II was $878.33 \pm$ 89.955 min which prolonged than group I which was $613.10 \pm 51.797 \mathrm{~min}$, mean onset time of Sensory block in group II was earlier $(4.36 \pm 0.81$ min) than Group I (4.84 $\pm 0.65 \mathrm{~min})$, mean onset time of Sensory block in group II was earlier (4.36 $\pm 0.81 \mathrm{~min})$ than Group I (4.84 $\pm 0.65 \mathrm{~min})$, mean onset time of Motor block in group II was earlier $(9.83 \pm 1.12 \mathrm{~min})$ than Group I $(10.85 \pm 0.79 \mathrm{~min})$ and mean duration of Motor block in group II was $621.67 \pm 46.76 \mathrm{~min}$ and in group I was $500.86 \pm$ $44.58 \mathrm{~min}$. This was similar to our study.

CONCLUSION: From our study, we concluded that addition of Clonidine $(2 \mu \mathrm{g} / \mathrm{kg}$ ) to $0.5 \%$ Ropivacaine in supraclavicular brachial plexus block has following advantages compare to $0.5 \%$ Ropivacaine alone.

1. Faster onset of analgesia, sensory and motor blockade

2. Longer duration of Analgesia, Sensory and motor Blockade.

3. No significant Difference in hemodynamic parameters (pulse rate, Blood pressure, $\mathrm{SpO} 2$ and respiratory rate) and no significant side effects and complications.

\section{ACKNOWLEDGEMENT: Nil}

\section{CONFLICTS OF INTEREST: Nil}

\section{REFERENCES:}

1. Stoelting RK and Hillier SC: Pharmacology and Physiology in Anesthetic Practice; $4^{\text {th }}$ edition.

2. Neal JM, Hebl JR, Gerancher JC and Hogano H: Brachial plexus anaesthesia: essentials of our current understanding. Reg. Anesth Pain Med 2002; 27: 402-28.

3. Gaitini LA, et al.: Does the addition of fentanyl to bupivacaine in caudal epidural block have an effect on the plasma level of catecholamines in children? Anesth Analg 2000; 90: 1029-3 3

4. De Mey JC, et al:: The influence of sufentanil and/or clonidine on the duration of analgesia after a caudal block for hypospadias repair surgery in children. Eur $\mathrm{J}$ Anaesthesiol 2000; 17: 379-82.

5. Constant I, et al.: Addition of clonidine or fentanyl to local anaesthetics prolongs the duration of surgical analgesia after single shot caudal block in children. Br J Anaesth 1998; 80: 294-8.

6. Baris S, et al.: Comparison of fentanyl-bupivacaine or midazolambupivacaine mixtures with plain bupivacaine for caudal anaesthesia in children. Paediatr Anaesth, 2003; 13: $126-3$.

7. Vercauteren $\mathrm{M}$ and Meert TF: Isobolographic analysis of the interaction between epidural sufentanil and bupivacaine in rats. Pharmacol Biochem Behav 1 997; 58: 237-42.

8. Palmer CM, et al.: Bupivacaine augments intrathecal fentanyl for labor analgesia. Anesthesiology 1999; 91: 849.

9. Madan R, et al.: A dose response study of clonidine with local anesthetic mixture for peribulbar block: a comparison of three doses. Anesth Analg 2001; 93: 1593-7.

10. Butterworth JF and Strichartz GR: The alpha 2-adrenergic agonists clonidine and guanfacine produce tonic and phasic block of conduction in rat sciatic nerve fibers. Anesth Analg 1993; 76: 295-301. 
11. Murphy DB et al.: Noval analgesia adjuncts for brachial plexus block. A systemic review. Anaesth Analg 2000; 1122-1128.

12. Eisenach JC, Dekock M and Klimscha W: Alpha (2) adrenergic agonists for regional anesthesia. A clinical review of clonidine (1984-1995). Anesthesiology 1996; 85: 655-74.

13. Chakraborty S, Chakrabarti J. Mandai MC, Harza A and Das S: Effect of clonidine as adjuvant in bupivacaineinduced supraclavicular brachial plexus block: A randomized controlled trial. Indian J Pharmacol 2010; 42: 74-7.

14. Rohan B, Singh PY and Gurjeet K: Addition of clonidine or lignocaine to ropivacaine for supraclavicular brachial plexus block: a comparative study; Singapore Med J. 2014; 55(4): 229-32.

15. Gupta S, Gadani HN and Thippeswamy HG: A comparative study between ropivacaine $30 \mathrm{ml}(0.75 \%)$ and ropivacaine $30 \mathrm{ml}(0.75 \%)$ with clonidine $150 \mu \mathrm{g}$ as an adjuvant in brachial plexus block through supraclavicular approach; Sudan Medical Monitor, January- March 2015; 10(1): 11-15.

16. Raut K, Pradhan BK, Routray SS and Mishra D: The Effects of two different doses of Clonidine as Adjuvant to Ropivacaine in Supraclavicular Brachial Plexus Block- A randomized controlled study; Annals of International Medical and Dental Research 2(1): 295-300.

17. Chatrath V, Sharan R, Kheterpal R, Kaur G, Ahuja J and Attri JP: Comparative evaluation of $0.75 \%$ ropivacaine with clonidine and $0.5 \%$ bupivacaine with clonidine in infraclavicular brachial plexus block; Anesth Essays Res. 2015; 9(2): 189-94.

18. Baj B, Tyagi V, Chaudhri RS and Derashri A: A comparative study of effects of clonidine added to ropivacaine versus plain ropivacaine during supra clavicular brachial plexus block; Journal of Evolution of Medical and Dental Sciences 2013; 2(52); 10228-10235.

19. Mohammad A, Goel S, Singhal A and Rae V: Clonidine as an Adjuvant to Ropivacaine in Supraclavicular Brachial Plexus Block: A randomized double blinded prospective study; International Journal of Contemporary Medical Research 2016; 3(5): 1293-1296.

20. Patel C, Parikh H, Bhavsar MM and Upadhyaya R: Clonidine as adjuvant to $0.75 \%$ ropivacaine in supraclavicular brachial plexus block for post operative analgesia: A single blind randomized controlled trial; IJBR 2014; 05(05).

21. Bafna U, Yadav N, Khandelwal M, Mistry T, Chatterjee $\mathrm{CS}$ and Sharma R: Comparison of $0.5 \%$ ropivacaine alone and in combination with clonidine in supraclavicular brachial plexus block; Indian Journal of Pain, 2015; 29(1): 41-45.

22. Routray SS, Biswal D, Raut K and Mishra D: The Effects of Clonidine on Ropivacaine in Supraclavicular Brachial Plexus Block; Sch.J.App.Med.Sci. 2013; 1(6): 887-893.

23. Patil KN and Singh ND: Clonidine as an adjuvant to ropivacaine-induced supraclavicular brachial plexus block for upper limb surgeries; Journal of Anaethesiology Clinical Pharmacology 2015; 31(3): 365-369.

\section{How to cite this article:}

Priyadarshi D, Gondalia D and Parmar V: Comparative study of ropivacaine with clonidine and ropivacaine alone in supraclavicular brachial plexus block. Int J Pharm Sci Res 2018; 9(6): 2456-62. doi: 10.13040/IJPSR.0975-8232.9(6).2456-62.

All @ 2013 are reserved by International Journal of Pharmaceutical Sciences and Research. This Journal licensed under a Creative Commons Attribution-NonCommercial-ShareAlike 3.0 Unported License.

This article can be downloaded to ANDROID OS based mobile. Scan QR Code using Code/Bar Scanner from your mobile. (Scanners are available on Google Playstore) 